\title{
Differences between mechanically stable and unstable chronic ankle instability subgroups when examined by arthrometer and FAAM-G
}

Heinz Lohrer ${ }^{1,2^{*}+}$, Tanja Nauck ${ }^{1 \dagger}$, Dominic Gehring ${ }^{2 \dagger}$, Sabrina Wissler ${ }^{2 \dagger}$, Bela Braag ${ }^{1,3}$ and Albert Gollhofer ${ }^{2 \dagger}$

\begin{abstract}
Background: The objective measurement of the mechanical component and its role in chronic ankle instability is still a matter of scientific debate. We analyzed known group and diagnostic validity of our ankle arthrometer. Additionally, functional aspects of chronic ankle instability were evaluated in relation to anterior talar drawer.

Methods: By manual stress testing, 41 functionally unstable ankles were divided as mechanically stable $(n=15)$ or mechanically unstable $(n=26)$. Ankle laxity was quantified using an ankle arthrometer. Stiffness values from the load displacement curves were calculated between 40 and $60 \mathrm{~N}$. Known group validity and eta ${ }^{2}$ were established by comparing manual and arthrometer testing results. Diagnostic validity for the ankle arthrometer was determined by a $2 \times 2$ contingency table. The functional ankle instability severity was quantified by the German version of the Foot and Ankle Ability Measure (FAAM-G). Stiffness (40-60 N) and FAAM-G values were correlated.
\end{abstract}

Results: Mechanically unstable ankles had lower 40-60 N stiffness values than mechanically stable ankles ( $p=0.006$ and $<0.001$ ). Eta for the relation between manual and arthrometer anterior talar drawer testing was 0.628 . With $5.1 \mathrm{~N} / \mathrm{mm}$ as cut-off value, accuracy, sensitivity, and specificity were $85 \%, 81 \%$, and $93 \%$, respectively.

The correlation between individual 40-60 N arthrometer stiffness values and FAAM-G scores was $r=0.286$ and 0.316 ( $p=0.07$ and 0.04).

Conclusions: In this investigation, the ankle arthrometer demonstrated a high diagnostic validity for the determination of mechanical ankle instability. A clear interaction between mechanical (ankle arthrometer) and functional (FAAM-G) measures could not be demonstrated.

Keywords: Chronic ankle instability, Ankle arthrometer, FAAM, Functional ankle instability, Mechanical ankle instability

\section{Background}

The term "chronic ankle instability" (CAI) was introduced in 2002 and is increasingly referenced since then [1]. It is generally agreed that CAI (Figure 1) is an "encompassing term" covering both functional ankle instability (FAI) and mechanical ankle instability (MAI) $[1,2]$. CAI is "the most commonly used term to describe subjects who report ongoing symptoms after an initial ankle sprain" [3]. Acute lateral ankle sprains have to be

\footnotetext{
* Correspondence: lohrer@smi-frankfurt.de

${ }^{\dagger}$ Equal contributors

'Institute for Sports Medicine, Otto-Fleck-Schneise 10, D-60528 Frankfurt am Main, Germany

${ }^{2}$ Department of Sport and Sport Science, University of Freiburg,

Schwarzwaldstraße 175, D-79117 Freiburg, Germany

Full list of author information is available at the end of the article
}

differentiated from CAI. It can take from 6 weeks to 3 months for ligament healing to be complete after acute ankle sprain [4]. "Copers" are defined as people who fully recover after an ankle sprain [5].

Within the literature at this time, however, it is obvious that the terms CAI, FAI, and MAI are not precisely defined and thus were not well separated in previous studies. Even recently, these terms have been used synonymously. A "consistent terminology" is demanded $[2,3,6]$. A systematic investigation has shown that the outcome in research is mainly affected by the definitions of CAI, FAI, and MAI [2]. In consequence, it is therefore proposed to exactly define the inclusion and exclusion criteria when investigating CAI [2,3]. More detailed analyses show that MAI and FAI interaction appears to be 


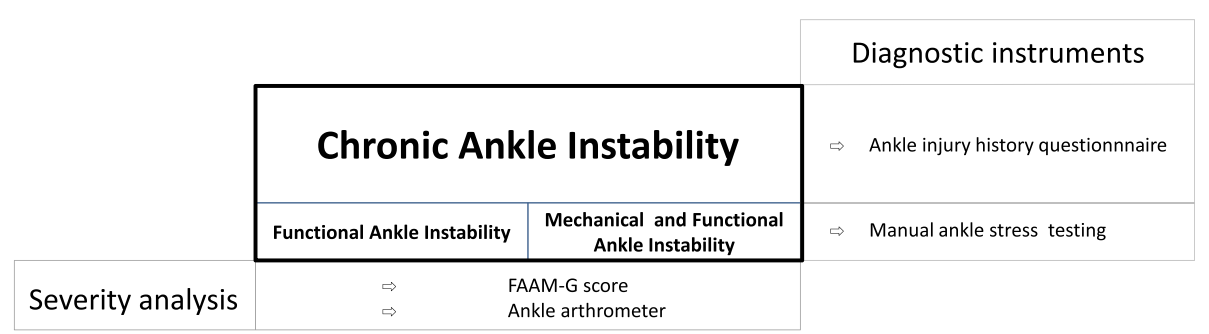

Figure 1 Schematic for the definitions and the respective test instruments used in the present study.

essential to get a thorough understanding of the different phenomena of CAI.

The concept of FAI was established in 1966 to describe "the tendency for the foot to give way after an ankle sprain" [7]. To explain "instabilities despite a mechanically stable ankle", sensorimotor pathway alterations and impaired neuromuscular control are assumed [8], and a broad variety of complaints was included [2]. With respect to the concept of MAI "pathologic laxity, impaired arthrokinematics and synovial and degenerative changes" have also been attributed $[9,10]$.

An Ankle Injury History Questionnaire has been introduced in 2008 to select CAI persons [11]. Recently, the International Ankle Consortium established "selection criteria for patients with chronic ankle instability in controlled research" [3]. Specifically, one significant ankle sprain, followed by "giving way," and/or recurrent sprain, and/or "feelings of instability" and persisting disability, documented with a self-reported foot and ankle function questionnaire is recommended [3]. The rating of MAI is considered as a "potential confounding factor" [3]. Thus, the impact of MAI remains controversial. Results from our clinical and experimental research [12,13] are in contrast with the assumption that "there has not been a definitive association of ankle laxity with CAI" [3]. Clinical literature nearly exclusively means MAI when using the term "CAI" and operative ligament reconstruction consistently results in both functionally and mechanically stable ankles [12-15].

MAI "is universally accepted as pathologic ligamentous laxity about the ankle-joint complex" [10]. This means that isolated ankle laxity (=hypermobility) without subjectively perceived symptoms is not a pathologic condition and can neither be labeled MAI nor FAI nor CAI [3].

Several instruments have been described to determine the severity of MAI or FAI [6]. There is no generally agreed gold standard to diagnose and quantify MAI [2]. Manual stress testing is widely accepted and proposed as standard to divide mechanically stable from mechanically unstable ankles [6,16-18]. Its accuracy, however, is still debated [19-23]. In the research setting, specific disadvantages of this procedure are rater dependency and its qualitative categorizing nature [10]. Recent literature has proposed to perform studies that "validate manual stress tests with instrumented arthrometry" [24]. Compared with arthroscopy, the sensitivity of anterior talar drawer (ATD) stress radiographs, ultrasound, and MRI to detect chronic anterior talofibular ligament injury was $92 \%, 100 \%$, and $92 \%$, respectively [25]. However, radiographic stress testing is still a matter of discussion $[26,27]$. To avoid radiation, several non-radiographic ankle stress testing devices have been developed [6,28]. Published normative values are relevant only for testing performed with one specific apparatus [29]. Generally accepted normative values do not exist, and therefore, the diagnostic use of ankle arthrometers is limited so far. We developed and validated an ankle arthrometer in a cadaveric study and in an in vivo pilot study $[28,30]$. Balance, strength, and self-report function questionnaires have been shown to quantify or to diagnose FAI $[9,28]$.

The main purpose of this study was to perform a "known group validation" [31] for our ankle arthrometer. Additionally, we evaluated the diagnostic validity of our ankle arthrometer. We finally questioned if an interaction exists between the mechanical (ankle arthrometer) and the functional (FAAM-G) measures.

\section{Methods}

This cross-sectional investigation is part of a larger study to experimentally evaluate the impact of CAI on involuntarily foot inversion during gait [13]. The study was approved by the Ethics Commission of the University of Freiburg, Germany and by the Landesärztekammer Hessen Ethics Committee. All participating subjects read and signed the informed consent form.

\section{Study population}

By announcement in the local press, 32 males were recruited (Figure 2). We included 26 subjects (Table 1 ). These "subjects" complained residual symptoms after ankle sprain(s) and were therefore CAI by definition [3]. Compared with these mildly affected CAI subjects, we assumed that patients who were waiting for ankle ligament reconstruction will suffer more severe CAI symptoms [32]. Therefore, 15 consecutive patients were 


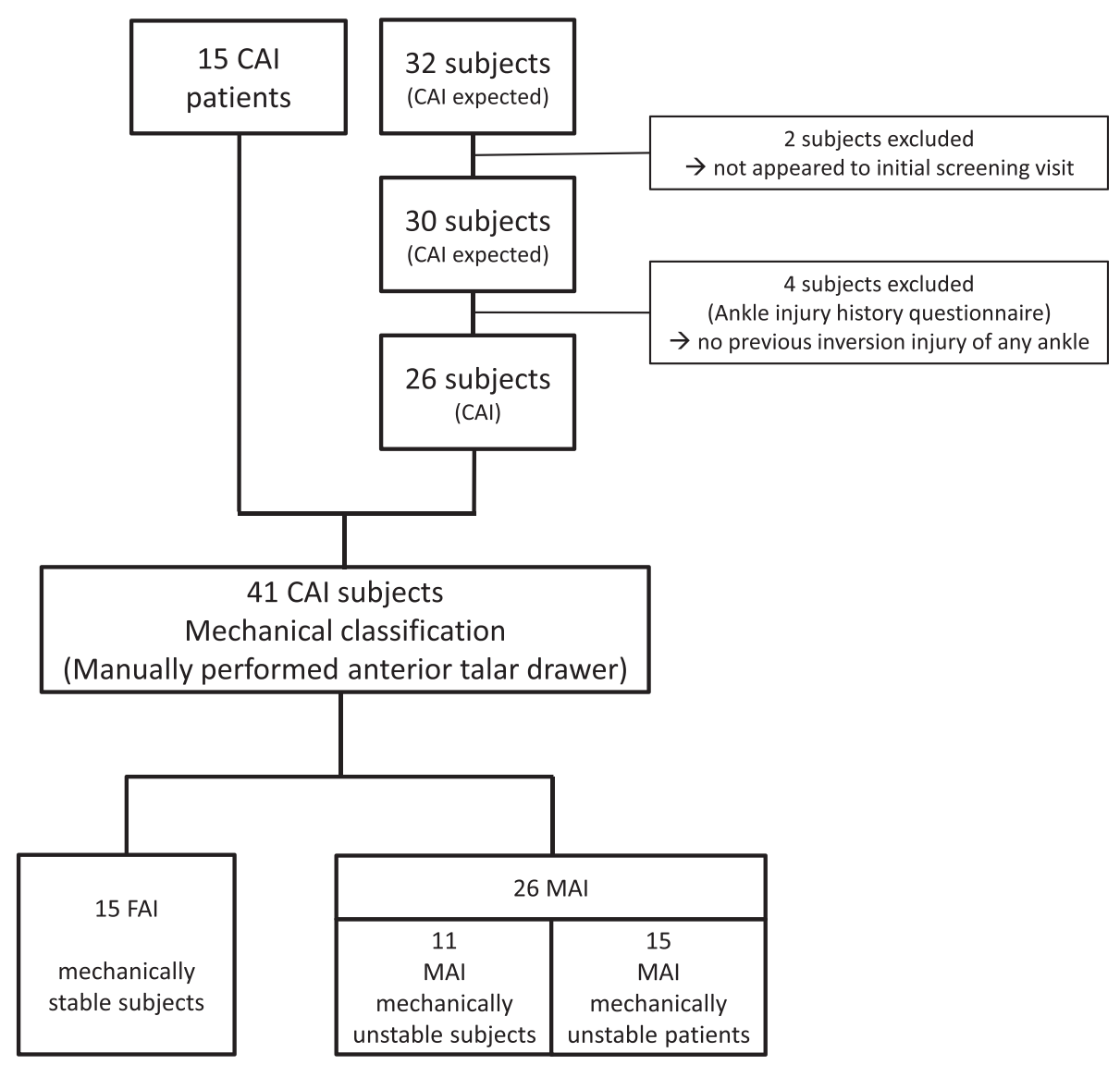

Figure 2 Flow chart to demonstrate the recruitment procedure of the tested groups under mechanical (MAI) and functional (FAI) considerations. $\mathrm{CAI}=$ chronic ankle instability. $\mathrm{MAI}=$ mechanical ankle instability. FAI = functional ankle instability.

selected in our sports medicine institute to represent a "patients' group" (Table 1). All these patients were diagnosed with MAI and were already described in a previous paper [32]. All subjects and patients were lower competitive level or recreational athletes (Table 1). Inclusion and exclusion criteria were based on the Ankle Injury History Questionnaire [11]: Subjects and patients were included when they reported at least one of the following criteria: a history of at least one ankle sprain more than 1 year ago. Additionally, actual symptoms of giving way, or feeling of giving way (at least once a month), and/or feelings of instability had to be stated (Table 1). Subjects and patients were separated based on the presence or absence of MAI (Figure 1). Persons with systemic diseases, neuromuscular disorders, and obesity (BMI greater than or equal to 30) were excluded. Subjects who complained of ankle pain as a primary symptom, who had an acute ankle sprain within the past 6 months or had previous foot and ankle surgery, fractures, or anatomic deformities of the lower extremities

Table 1 Anthropometrics and data from the individual histories for the tested group

\begin{tabular}{|c|c|c|c|c|c|c|c|c|c|c|}
\hline Classification & No. & $\begin{array}{l}\text { Age } \\
\text { (years) }\end{array}$ & $\begin{array}{l}\text { Height } \\
(\mathrm{cm})\end{array}$ & $\begin{array}{l}\text { Weight } \\
\text { (kg) }\end{array}$ & Right/left & AAS & $\begin{array}{l}\text { Previous ankle } \\
\text { sprains }\end{array}$ & $\begin{array}{l}\text { Feeling of } \\
\text { instability }\end{array}$ & Pain & Limitation \\
\hline \multirow[t]{2}{*}{ FAl subjects } & 15 & $24.9 \pm 2.3$ & $184.7 \pm 6.2$ & $84.3 \pm 11.2$ & $6 / 9$ & $8.3 \pm 1.2$ & $2.8 \pm 3.8$ & $6 / 9$ & $5 / 9$ & $6 / 8$ \\
\hline & & [22-29] & [174.0-193.0] & [61.6-106.6] & & [5-9] & {$[0-12]$} & & & \\
\hline \multirow[t]{2}{*}{ MAI subjects } & 11 & $26.3 \pm 4.7$ & $180.1 \pm 5.1$ & $77.4 \pm 5.5$ & $3 / 8$ & $7.5 \pm 1.3$ & $5.2 \pm 5.8$ & $7 / 7$ & $3 / 8$ & $3 / 8$ \\
\hline & & [20-38] & [173.5-187.0] & {$[67.5-88.4]$} & & [6-9] & {$[1-20]$} & & & \\
\hline \multirow[t]{2}{*}{ MAI patients } & 15 & $32.9 \pm 13.5$ & $175.9 \pm 7.6$ & $70.5 \pm 14.7$ & $5 / 10$ & $6.8 \pm 2.4$ & $6.2 \pm 3.9$ & $11 / 11$ & $14 / 14$ & $14 / 14$ \\
\hline & & {$[16-57]$} & [165.0-190.0] & [58.0-110.0] & & [2-9] & {$[1-10]$} & & & \\
\hline
\end{tabular}


were also excluded. Persons who presented more than 10 degrees of knee hyperextension in manual testing were also excluded.

\section{Testing procedure}

Included subjects initially filled out the Ankle Injury History [11] and the German version of the Foot and Ankle Ability Measure questionnaire (FAAM-G) to assess the severity of pain and disability. The two subscales of the instrument relate to activities of daily living (standing, walking, squatting, personal hygiene, working, and leisure time activities) and evaluate the ability to play sport. The maximum FAAM-G score is 100 and represents a pain free and unrestricted level of physical function [34]. One FAAM-G questionnaire was filled out per patient. One investigator (TN) was present during this process.

Physical examination was performed and documented by a second independent investigator specialized in foot and ankle (HL). He was blinded to the questionnaires' results and was unaware about the subjects' functional ankle status. Mechanical ankle stability was evaluated by manual ATD [16,35]. Each ankle was categorized as "mechanically stable" (=no ATD) or as "mechanically unstable" (=positive ATD).

Finally, stress testing with the ankle arthrometer was conducted. Our ankle arthrometer is a non-radiographic device to objectively quantify ATD. It has already proven its validity in a cadaver experiment [30] and in vivo $[28,32]$. In principle, this apparatus pulls the heel anteriorly with respect to the fixed lower leg $(8 \mathrm{~mm} / \mathrm{s}$, maximum force $200 \mathrm{~N}$ ), and the respective distance is measured by a linear potentiometer (Additional file 1). From the resulting load-deformation curve, stiffness was calculated (Figure 3) $[28,32,30]$. The toe region $(40-60 \mathrm{~N})$ represents the tibiotalar translation (ATD) while the stiffness in the upper region (125-175 N) of the loaddeformation curve indicates the rigidity of the ankle and its encompassing soft tissues with the talus already anteriorly translated to its end position [28,32]. Ankle arthrometer calculations were based on the mean values obtained from three consecutive measurements in each ankle (three trial average). Analyzes were based on one ankle per person. If both ankles were CAI, further analyses were focused to the side performing worse in the manually performed ATD test (11 subjects). In 15 subjects, there was no side difference and the side to be further considered was randomly chosen.

\section{Grouping}

In line with our previous work [13], we diagnosed MAI when FAI symptoms were present and manual ankle stress testing revealed mechanical ankle instability (Figure 1). Respectively, 15 FAI subjects, 11 MAI subjects, and 15 MAI patients were grouped to test known group validity. Further analyses (diagnostic validity, correlation, and eta) were based on two groups (15 FAI vs. $26 \mathrm{MAI}$ ) combining the MAI subgroups (Figure 2).

\section{Statistical analysis}

The SPSS statistical package 20.0 for windows (SPSS Inc., Chicago, IL) was used for statistical analysis. The

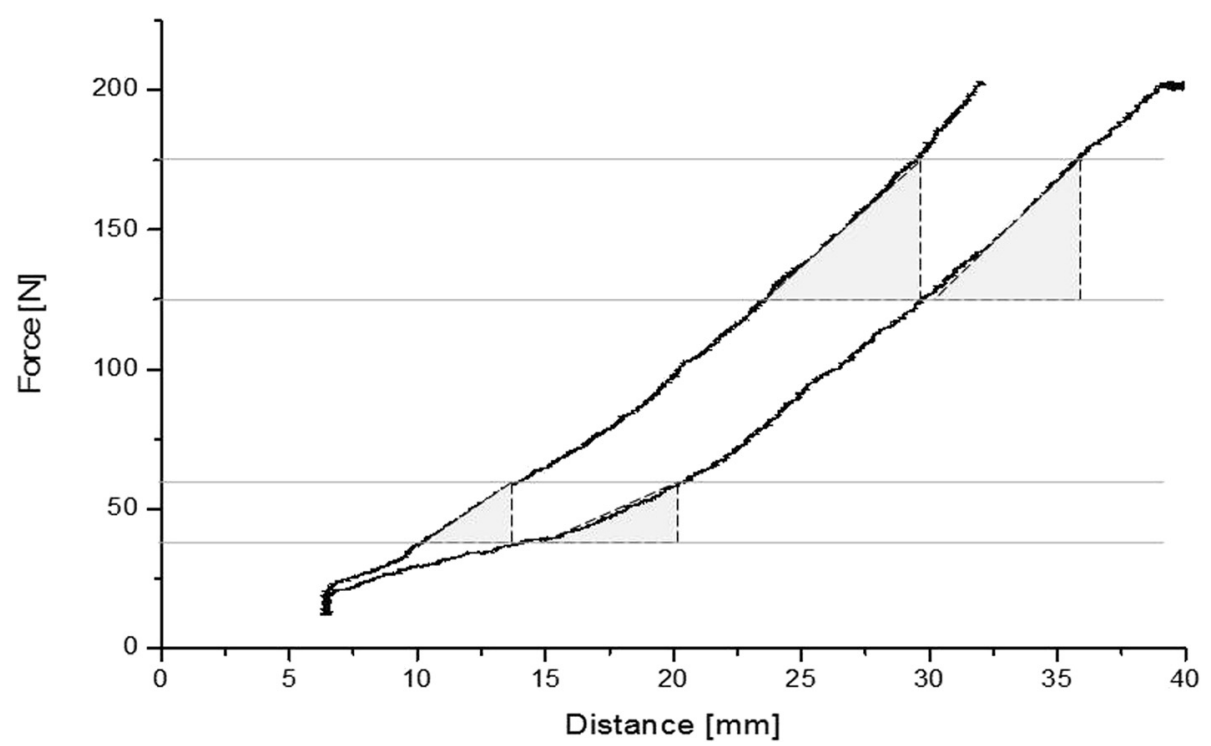

Figure 3 Two typical load-deformation curves. The left one is selected from a mechanically stable and the right one from a mechanically unstable ankle. The stiffness was calculated from the slopes (slope $=\Delta$ Force $[\mathrm{N}] / \Delta$ Distance $[\mathrm{mm}]$ ) in the intervals from 40 to $60 \mathrm{~N}$ and 125 to $175 \mathrm{~N}$. The stiffness is not different in the 125-175 N intervals but the stable subject's $40-60 \mathrm{~N}$ slopes are steeper. 
Kolmogorov-Smirnov test was performed to test for normal distribution. Known group validity [30] was evaluated by comparing the arthrometer results between FAI $(n=15)$, MAI subjects $(n=11)$, and MAI patients $(n=15)$ using a one-way analysis of variance with Turkey's post hoc procedure. Post hoc analyzed power for the number of subjects within the groups was $1-\beta=0.998$ with $\alpha=$ 0.05 . Eta for the relation between manual and arthrometer ATD testing was calculated. A receiver operating characteristic curve (ROC) analysis was calculated to determine which 40-60 N stiffness cut-off value was most suitable to discriminate between the mechanically stable $(n=15)$ and the mechanically unstable $(n=26)$ ankles. As a result of the ROC analysis, the diagnostic validity parameters of the arthrometer (sensitivity, specificity, positive, and negative predictive value) were calculated. The interaction of FAI $(n=15)$ and MAI $(n=26)$ was determined by a Pearson correlation analysis between the individual ankle arthrometer findings and the respective FAAM-G results. Tests were considered significant at a level of $p<0.05$.

\section{Results}

The mean values of the 40-60 N stiffness analyses and for both FAAM-G subscales were highest in the FAI group and lowest in the patients (Tables 2 and 3, Figures 4 and 5).

In the low region, (40-60 N) of the load-deformation curves MAI subjects' and patients' ankles had significantly lower stiffness than FAI ankles $(p=0.006$ and $<0.001)$. There was no difference discernible between MAI subjects and patients' ( $p=0.224$; Figure 4; Tables 2 and 3). In the 125-175 N load region of the load-deformation curves, no difference existed, when the groups were compared (all $p>0.468$ ).

Eta for the relation between manual and arthrometer ATD testing was 0.628 .

Regarding the FAAM-G subscale for activities of daily living, the FAI group was different from the patients' group $(p=0.011)$. The sport subscale revealed lower scores for the patients when compared with both FAI and MAI subjects ( $p=0.002$ and 0.024 ; Tables 2 and 3$)$.
ROC calculation (Figure 6) revealed the lowest error classification rate $(11 \%)$ for a cut-off stiffness value of $5.1 \mathrm{~N} / \mathrm{mm}$. The resulting sensitivity (true positive rate) of the measurements was $81 \%$ and the specificity was $93 \%$. The positive and negative predictive values were $96 \%$ and $94 \%$, respectively.

The correlations between individual 40-60 N arthrometer stiffness values and FAAM-G scores for activities of daily living and sports were $r=0.286 \quad(p=0.07$ and $r=0.316(p=0.04)$, respectively.

\section{Discussion}

Known group validation confirmed that the assumed difference between mechanically stable (FAI) and unstable (MAI) subgroups of CAI can be measured by ankle arthrometry $(p=0.006$ and $<0.001)$. With the available numbers, patients and MAI subjects did not differ in this respect $(p=0.224)$. With a cut-off value of $5.1 \mathrm{~N} /$ $\mathrm{mm}$ a high diagnostic validity of the arthrometer is proven, supporting the results of a previous cadaver study [30].

CAI probably represents a continuum from mechanically stable to mechanically unstable ankles and dichotomous grading (FAI and MAI) is not representing the whole truth. However, experimental research found no evidence that MAI and FAI fall at different places within that continuum with MAI presenting more functional symptoms [13].

The FAAM-G results suggest that FAI subjects complain of less severe symptoms than MAI subjects and patients. However, only the sport subscale revealed relevant differences between MAI subjects and patients ( $p=$ 0.024). A poor to medium strength correlation was found between arthrometer and FAAM-G results. Our clinical [28] and recent experimental work [13] confirms these findings and demonstrates that both factors may "substantially interact" [9]. Previous research using ankle arthrometers and stress radiography also detected greater ATD in functionally unstable ankles [24,32].

A control group without previous ankle injury was not recruited for the present study. This comparison,

Table 2 Stiffness and FAAM-G results when categorized by manual instability testing; values are given as [N/mm]

\begin{tabular}{|c|c|c|c|c|c|}
\hline Classification & No. & $\begin{array}{l}\text { Stiffness } 40-60 \mathrm{~N} \\
(\mathrm{~N} / \mathrm{mm})\end{array}$ & $\begin{array}{l}\text { Stiffness } 125-175 \mathrm{~N} \\
(\mathrm{~N} / \mathrm{mm})\end{array}$ & $\begin{array}{l}\text { FAAM-G } \\
\text { ADL }\end{array}$ & $\begin{array}{l}\text { FAAM-G } \\
\text { Sports }\end{array}$ \\
\hline \multirow[t]{2}{*}{ FAl subjects } & 15 & $7.1 \pm 1.8$ & $9.4 \pm 1.4$ & $96.9 \pm 5.6$ & $88.2 \pm 13.8$ \\
\hline & & {$[3.0-10.1]$} & {$[7.2-12.7]$} & [80-100] & [63-100] \\
\hline \multirow[t]{2}{*}{ MAI subjects } & 11 & $5.0 \pm 1.8$ & $8.5 \pm 1.2$ & $94.1 \pm 7.1$ & $83.8 \pm 13.1$ \\
\hline & & [3.2-9.4] & [6.9-10.5] & [80-100] & [59-100] \\
\hline \multirow[t]{2}{*}{ MAI patients } & 15 & $3.9 \pm 1.2$ & $8.9 \pm 2.8$ & $88.1 \pm 9.7$ & $64.4 \pm 22.7$ \\
\hline & & [1.9-5.9] & {$[4.7-13.7]$} & [71-100] & [16-100] \\
\hline
\end{tabular}


Table 3 Stiffness and FAAM-G results when categorized by manual instability testing; respective statistical analyzes

\begin{tabular}{|c|c|c|c|c|c|}
\hline \multicolumn{2}{|l|}{ Classification } & $\begin{array}{l}\text { Stiffness } 40-60 \mathrm{~N} \\
p \text { value }\end{array}$ & $\begin{array}{l}\text { Stiffness } 125-175 \mathrm{~N} \\
p \text { value }\end{array}$ & $\begin{array}{l}\text { FAAM-G ADL } \\
p \text { value }\end{array}$ & $\begin{array}{l}\text { FAAM-G Sports } \\
p \text { value }\end{array}$ \\
\hline \multirow[t]{2}{*}{ FAI subjects vs. } & MAI subjects & 0.006 & 0.468 & 0.615 & 0.797 \\
\hline & MAI patients & $<0.001$ & 0.773 & 0.011 & 0.002 \\
\hline MAI subjects vs. & MAl patients & 0.224 & 0.844 & 0.142 & 0.024 \\
\hline
\end{tabular}

Significant findings are italicized.

however, was recently published demonstrating clear between group differences $(p<0.01)$ for the ankle arthrometry and FAAM-G [32]. An individual comparison to the uninjured side was not performed because current research has demonstrated evidence for a central dysfunction in CAI subjects affecting also the uninjured leg [36].

Even if there is still disagreement with its usefulness [19-23], manual stress testing is considered as standard to diagnose MAI [6,16-18,35,37]. Experimental cadaver studies found insufficient interrater reliability $[18,23]$ but excellent intraobserver reliability $(r=0.94)$ for ATD and sensitivity and specificity, respectively, were $100 \%$ and $66.67 \%$ [18]. Validated against surgery and arthrography, the specificity and sensitivity of physical examination to detect an ankle ligament lesion were found to be $84 \%$ and $96 \%$, respectively, and there was also a good interobserver agreement (kappa values 0.5 to 1.0) [16]. Intrarater reliability $(r=0.9 ; p<0.001)$ for the manually performed ATD test is described to be excellent [38]. In an in vivo experimental study, the manually performed ATD demonstrated good sensitivity $(74 \%$ or $83 \%$, depending on the set standard) and strong correlation (rho $=0.62, p=0.02$ ) when compared with ultrasound laxity measurement [19]. Concluding from these results, we feel that the ATD test, specifically when performed by a single and experienced observer, is currently the most objective tool to differentiate mechanically stable from unstable ankles. Therefore, we selected this test as standard for diagnostic validity testing.

Resulting from the eta test, a "moderate to large" relation was proven between manually and arthrometer ATD testing. This indicates that the arthrometer is suitable for quantifying ATD instability. In general, it would be preferable to validate the arthrometer with another continuous measure, e.g., stress radiographs. However, the validity of stress radiographs in vivo is still under intensive debate $[26,27]$ and was not performed due to ethical considerations (radiation). Additionally, an arthrometer validation against stress radiographs was already

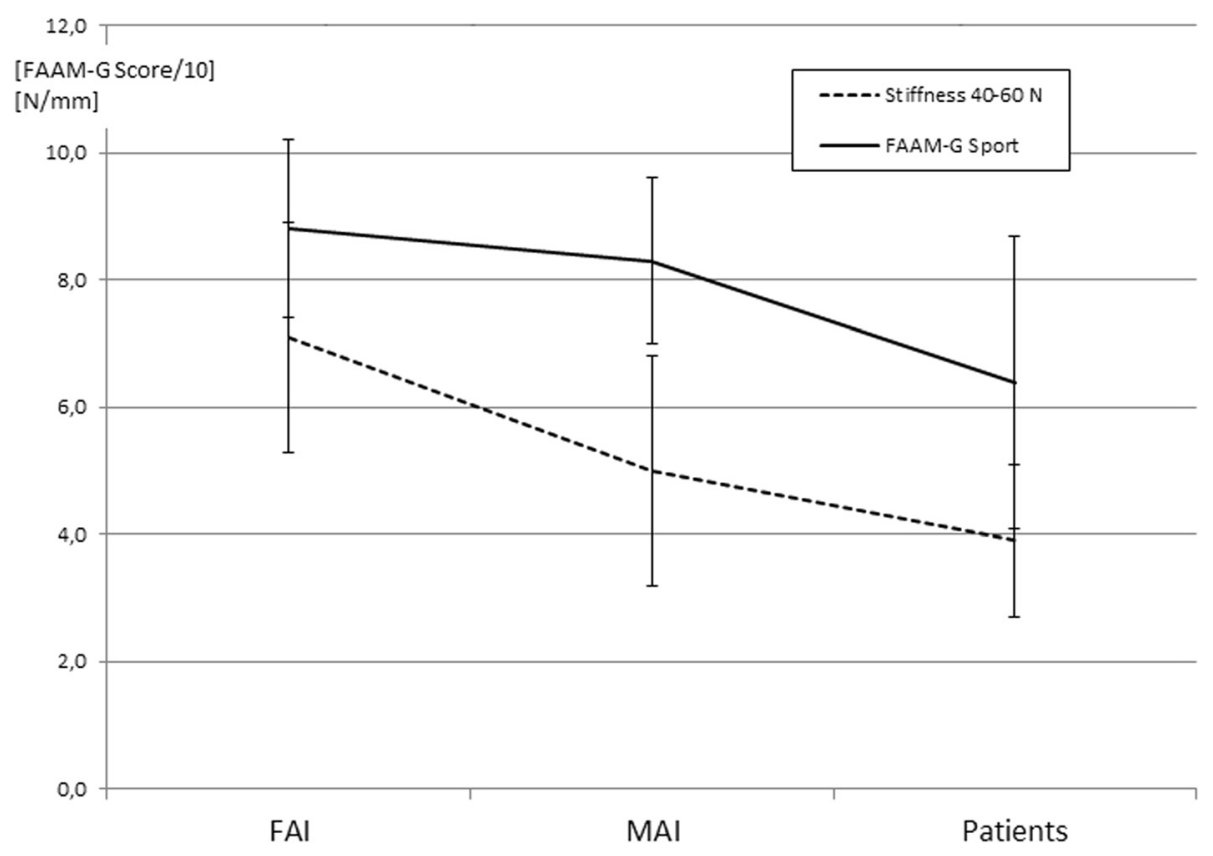

Figure 4 Mean + SD demonstrating the FAAM-G scores/10 and the respective stiffness. Mean + SD demonstrating the FAAM-G scores/10 and the respective stiffness in the low region $(40-60 \mathrm{~N})$ of the load-deformation curves obtained from the ankle arthrometer. The $p$ values can be extracted from Table 3. 


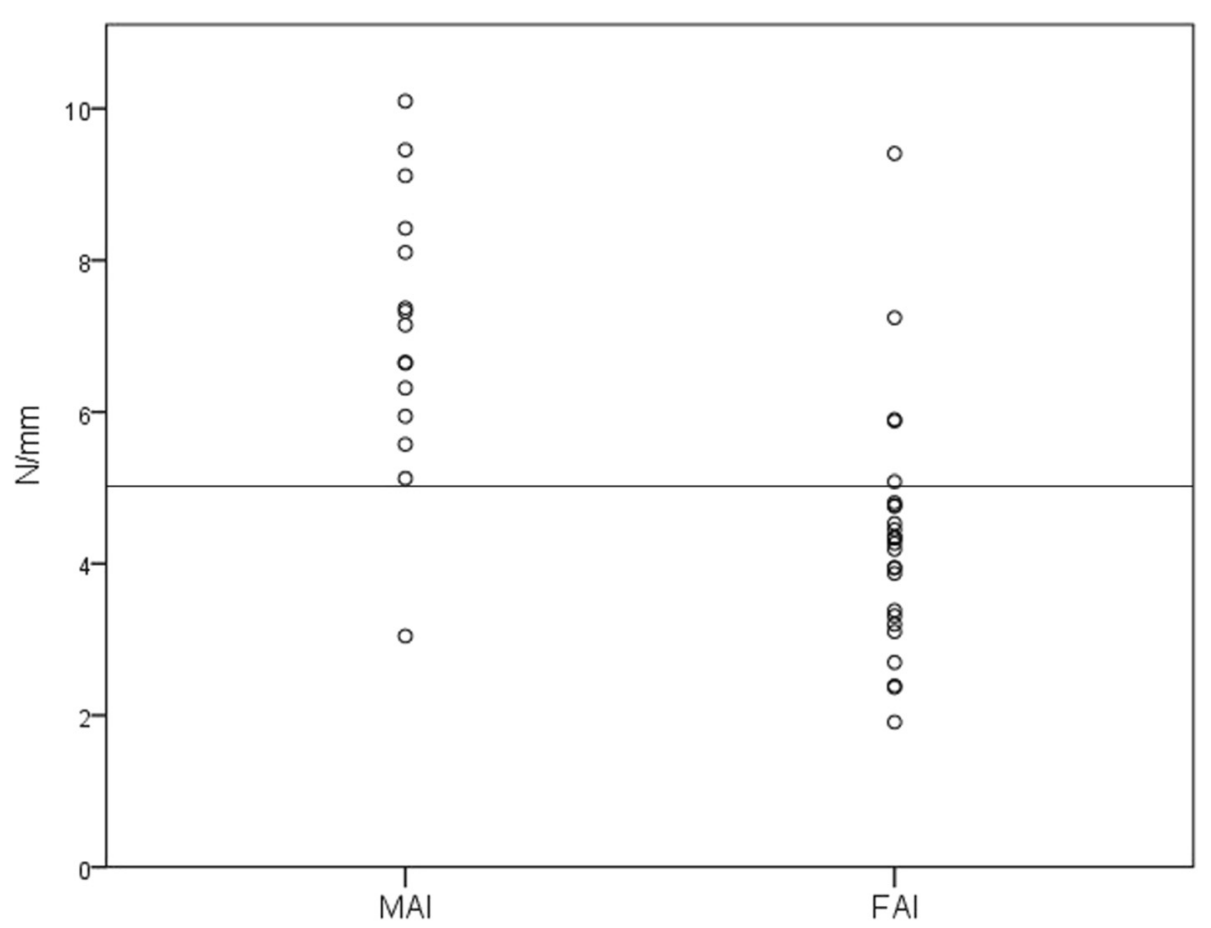

Figure 5 Distribution of stiffness values. Individual 40-60 N stiffness values for the functional ankle instability (FAl) and the mechanical ankle instability (MAI) group. The line $(5.1 \mathrm{~N} / \mathrm{mm}$ ) represents the best cut off value (error classification rate $=11 \%$ ) to discriminate between FAI and MAI with a sensitivity of $81 \%$ and a specificity of $93 \%$.

successfully performed previously in a cadaver experiment [30].

The major clinical implication of this study is the generation of a cut-off value to differentiate mechanical stable from mechanically unstable ankles in CAI. Only a weak relation between mechanical (arthrometer) and functional (FAAM-G) measures was demonstrated with more subjective limitations in MAI. Therefore, manual testing or arthrometry should be performed in all persons presenting with FAI symptoms because MAI persons seem to be "more prone to recurrent ankle sprains" [13] and need further mechanical support (tape, bandage, brace, or surgery).

\section{Limitations of this study}

This study was planned and performed before the "International Ankle Consortium" published its "selection criteria for patients with chronic ankle instability in

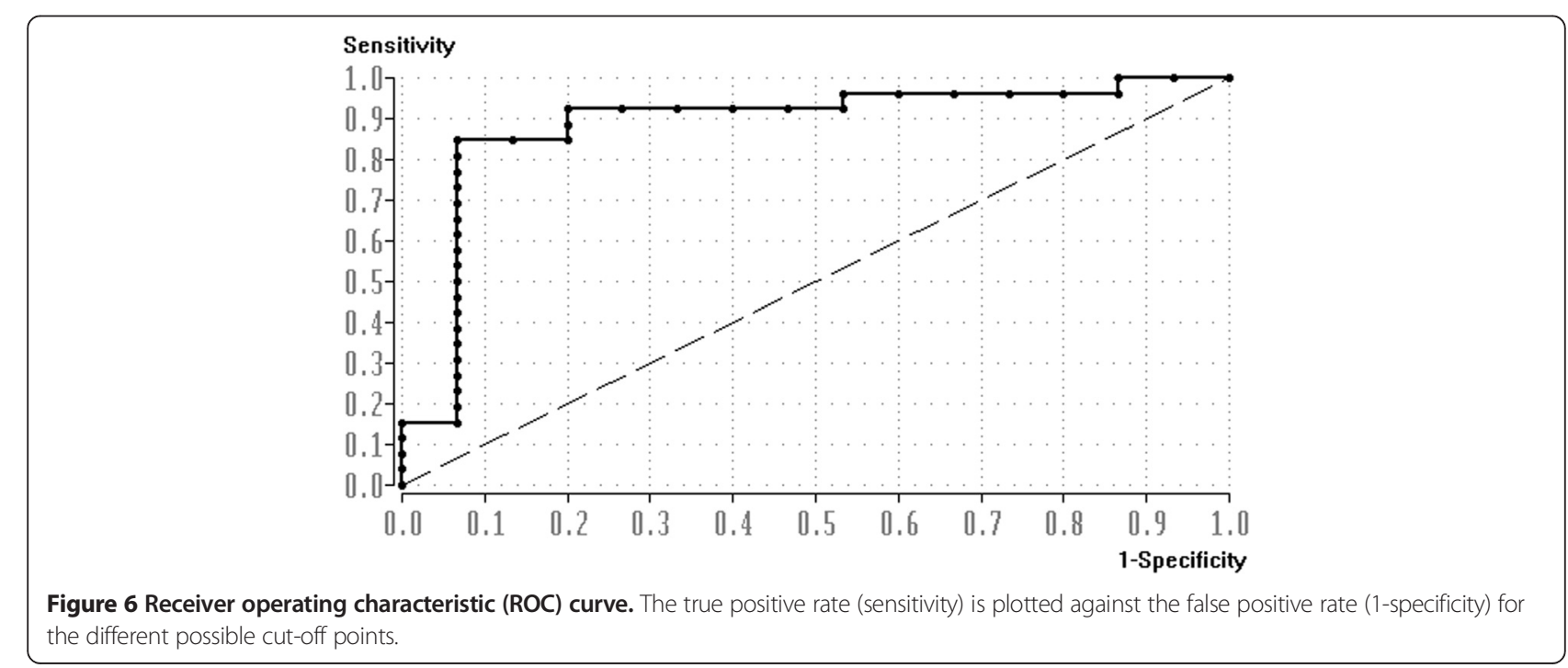


controlled research" [3]. However, our inclusion criteria are consistent with these criteria: (a) previous significant ankle sprain, (b) giving way, and/or recurrent sprain, and/or feelings of instability, and (c) a "self-reported foot and ankle function questionnaire is recommended". With respect to the FAAM-G activities of daily living and sport subscales, cut-off values of $90 \%$ and $80 \%$, respectively, are proposed as upper limits for inclusion [3]. Our FAI and MAI subject groups scored close to while the patients scored clearly below these limits. Our selection criteria excluded copers (no residual symptoms after an ankle sprain more than 1 year ago).

All participants in our study were male, and the results may not be generalizable to females. But this is not a limitation but rather strength. Relevant differences between genders were reported using another ankle arthrometer [29]. Therefore, including females could likely bias the results and remains the scope for further research.

\section{Conclusions}

Compared with manual ankle instability testing, our ankle arthrometer proved to be a valid instrument to differentiate mechanically stable from mechanically unstable ankles in male subjects and patients. There are several benefits of the ankle arthrometer stiffness assessment to recommend its use in clinical practice. The ankle arthrometer provides rater independent, continuous data and is radiation free. The ankle arthrometer better addresses the mechanical component, whereas the FAAM-G better addresses the functional component. We could demonstrate only a weak interaction (correlation) between functional (FAAM-G) and mechanical (arthrometry) measures. For further clinical practice and scientific CAI research, both measures should be collected.

\section{Additional file}

Additional file 1: Video clip to demonstrate the make, model, and function of the used ankle arthrometer. Here, an ankle model is placed in the arthrometer for better demonstration of the principle of its functioning.

\footnotetext{
Abbreviations

FAAM-G: Foot and ankle ability measure-German version; CAl: Chronic ankle instability; FAl: Functional ankle instability; MAl: Mechanical ankle instability; ATD: Anterior talar drawer; MRI: Magnetic resonance imaging; BMI: Body mass index; ROC: Receiver operating characteristic.
}

\section{Competing interests}

The authors declare that they have no competing interests.

\section{Authors' contributions}

$\mathrm{HL}$ conceived the study, participated in its design, performed data acquisition, interpreted the data, and drafted the manuscript. TN conceived the study, participated in its design, performed data acquisition, analyzed, and interpreted the data and helped to draft the manuscript. AG, DG, SW, and BB conceived the study, participated in its design, analyzed and interpreted the data, and helped to draft the manuscript. All authors read and approved the final manuscript.

\section{Acknowledgements}

This study was granted in part by the Federal Institute of Sports Sciences (BISp, II A 1-071502/08) and the Hessian Ministry of the Interior and for Sport. These sponsors were not involved in the discharge or organization of the study. The authors thank Dr. H. Ackermann (Institut für Biostatistik und Mathematische Modellierung, Zentrum der Gesundheitswissenschaften, Klinikum und Fachbereich Medizin der Goethe-Universität Frankfurt am Main, Germany) for his statistical support.

\section{Author details}

${ }^{1}$ Institute for Sports Medicine, Otto-Fleck-Schneise 10, D-60528 Frankfurt am Main, Germany. ${ }^{2}$ Department of Sport and Sport Science, University of Freiburg, Schwarzwaldstraße 175, D-79117 Freiburg, Germany. ${ }^{3}$ Johann Wolfgang Goethe-University, Theodor-Stern-Kai 7, D-60590 Frankfurt, Germany.

Received: 18 December 2014 Accepted: 17 February 2015

Published online: 08 March 2015

\section{References}

1. Hertel J. Functional anatomy, pathomechanics, and pathophysiology of lateral ankle instability. J Athl Train. 2002;37:364-75.

2. Delahunt E, Coughlan GF, Caulfield B, Nightingale EJ, Lin CW, Hiller CE. Inclusion criteria when investigating insufficiencies in chronic ankle instability. Med Sci Sports Exerc. 2010:42:2106-21.

3. Gribble PA, Delahunt E, Bleakley C, Caulfield B, Docherty CL, Fourchet F, et al. Selection criteria for patients with chronic ankle instability in controlled research: a position statement of the International Ankle Consortium. J Orthop Sports Phys Ther. 2013;43:585-91.

4. Hubbard TJ, Hicks-Little CA. Ankle ligament healing after an acute ankle sprain: an evidence-based approach. J Athl Train. 2008;43:523-9.

5. Wikstrom EA, Tillman MD, Chmielewski TL, Cauraugh JH, Naugle KE, Borsa PA. Discriminating between copers and people with chronic ankle instability. J Athl Train. 2012;47:136-42.

6. Cordova ML, Sefton JEM, Hubbard TJ. Mechanical joint laxity associated with chronic ankle instability: a systematic review. Sports Health: A Multidisciplinary Approach. 2010;2:452-9.

7. Freeman MA. Instability of the foot after injuries to the lateral ligament of the ankle. J Bone Joint Surg (Br). 1965;47:669-77.

8. Hass CJ, Bishop MD, Doidge D, Wikstrom EA. Chronic ankle instability alters central organization of movement. Am J Sports Med. 2010;38:829-34.

9. Hubbard TJ, Kramer LC, Denegar CR, Hertel J. Correlations among multiple measures of functional and mechanical instability in subjects with chronic ankle instability. J Athl Train. 2007:42:361-6.

10. Hiller CE, Kilbreath SL, Refshauge KM. Chronic ankle instability: evolution of the model. J Athl Train. 2011;46:133-41.

11. Hubbard TJ. Ligament laxity following inversion injury with and without chronic ankle instability. Foot Ankle Int. 2008;29:305-11.

12. Nauck T, Lohrer H. Anatomische Stabilisation des Kapselbandapparates am oberen Sprunggelenk: 1-Jahres Ergebnisse im Längsschnitt. Fuß \& Sprunggelenk. 2013;11:9-14.

13. Gehring D, Faschian K, Lauber B, Lohrer H, Nauck T, Gollhofer A. Mechanical instability destabilises the ankle joint directly in the ankle-sprain mechanism. Br J Sports Med. 2014;48:377-82.

14. Petrera M, Dwyer T, Theodoropoulos JS, Ogilvie-Harris DJ. Short- to medium-term outcomes after a modified Brostrom repair for lateral ankle instability with immediate postoperative weightbearing. Am J Sports Med. 2014;42:1542-8.

15. Maffulli N, Del BA, Maffulli GD, Oliva F, Testa V, Capasso G, et al. Isolated anterior talofibular ligament Brostrom repair for chronic lateral ankle instability: 9-year follow-up. Am J Sports Med. 2013;41:858-64.

16. van Dijk CN, Lim LS, Bossuyt PM, Marti RK. Physical examination is sufficient for the diagnosis of sprained ankles. J Bone Joint Surg (Br). 1996;78:958-62.

17. Frey C, Bell J, Teresi L, Kerr R, Feder K. A comparison of MRI and clinical examination of acute lateral ankle sprains. Foot Ankle Int. 1996;17:533-7. 
18. Vaseenon T, Gao Y, Phisitkul P. Comparison of two manual tests for ankle laxity due to rupture of the lateral ankle ligaments. lowa Orthop $\mathrm{J}$. 2012;32:9-16.

19. Croy T, Koppenhaver S, Saliba S, Hertel J. Anterior talocrural joint laxity: diagnostic accuracy of the anterior drawer test of the ankle. J Orthop Sports Phys Ther. 2013:43:911-9.

20. Kerkhoffs GM, Blankevoort L, van Poll D, Marti RK, van Dijk CN. Anterior lateral ankle ligament damage and anterior talocrural-joint laxity: an overview of the in vitro reports in literature. Clin Biomech (Bristol, Avon). 2001;16:635-43.

21. Schwieterman B, Haas D, Columber K, Knupp D, Cook C. Diagnostic accuracy of physical examination tests of the ankle/foot complex: a systematic review. Int I Sports Phys Ther. 2013;8:416-26.

22. Wilkin EJ, Hunt A, Nightingale EJ, Munn J, Kilbreath SL, Refshauge KM. Manual testing for ankle instability. Man Ther. 2012;17:593-6.

23. Fujii T, Luo ZP, Kitaoka HB, An KN. The manual stress test may not be sufficient to differentiate ankle ligament injuries. Clin Biomech (Bristol, Avon). 2000;15:619-23.

24. Hubbard TJ, Kaminski TW, Vander Griend RA, Kovaleski JE. Quantitative assessment of mechanical laxity in the functionally unstable ankle. Med Sci Sports Exerc. 2004;36:760-6.

25. Oae K, Takao M, Uchio Y, Ochi M. Evaluation of anterior talofibular ligament injury with stress radiography, ultrasonography and MR imaging. Skeletal Radiol. 2010;39:41-7.

26. Frost SC, Amendola A. Is stress radiography necessary in the diagnosis of acute or chronic ankle instability? Clin J Sport Med. 1999;9:40-5.

27. Lohrer $\mathrm{H}$, Nauck T, Arentz S, Schöll J. Observer reliability in ankle and calcaneocuboid stress radiography. Am J Sports Med. 2008:36:1143-9.

28. Nauck T, Lohrer H, Gollhofer A. Clinical evaluation of a new noninvasive ankle arthrometer. Phys Sportsmed. 2010;38:55-61.

29. Schwarz NA, Kovaleski JE, Heitman RJ, Gurchiek LR, Gubler-Hanna C. Arthrometric measurement of ankle-complex motion: Normative values. J Athl Train. 2011:46:126-32.

30. Nauck T, Lohrer H, Gollhofer A. Evaluation of arthrometer for ankle instability: a cadaveric study. Foot Ankle Int. 2010;31:612-8.

31. Litwin MS. How to assess and interpret survey psychometrics. Thousand Oaks, California: Sage Publications Inc.; 2003.

32. Lohrer H, Nauck T, Gehring D, Gollhofer A. Ankle arthrometry for evaluation of the mechanical component in chronic ankle instability. Sportverletz Sportschaden. 2013;27:85-90

33. Halasi T, Kynsburg A, Tallay A, Berkes I. Development of a new activity score for the evaluation of ankle instability. Am J Sports Med. 2004;32:899-908.

34. Nauck T, Lohrer H. Translation, cross-cultural adaption and validation of the German version of the foot and ankle ability measure for patients with chronic ankle instability. Br J Sports Med. 2011;45:785-90.

35. Phisitkul P, Chaichankul C, Sripongsai R, Prasitdamrong I, Tengtrakulcharoen P, Suarchawaratana S. Accuracy of anterolateral drawer test in lateral ankle instability: a cadaveric study. Foot Ankle Int. 2009;30:690-5.

36. McKeon PO, Hertel J. Systematic review of postural control and lateral ankle instability, part I: can deficits be detected with instrumented testing. J Athl Train. 2008;43:293-304

37. Tohyama H, Beynnon BD, Renstrom PA, Theis MJ, Fleming BC, Pope MH. Biomechanical analysis of the ankle anterior drawer test for anterior talofibular ligament injuries. J Orthop Res. 1995;13:609-14.

38. Baumhauer JF, Alosa DM, Renstrom AF, Trevino S, Beynnon B. Test-retest reliability of ankle injury risk factors. Am J Sports Med. 1995;23:571-4.

\section{Submit your next manuscript to BioMed Central and take full advantage of:}

- Convenient online submission

- Thorough peer review

- No space constraints or color figure charges

- Immediate publication on acceptance

- Inclusion in PubMed, CAS, Scopus and Google Scholar

- Research which is freely available for redistribution 